\title{
OCCUPIED VOLUME INTEGRITY TESTING: ELASTIC TEST RESULTS AND ANALYSES
}

\author{
Michael Carolan \\ Michelle Muhlanger \\ Benjamin Perlman \\ David Tyrell \\ Volpe National Transportation Systems Center \\ US Department of Transportation \\ Cambridge, MA 02142
}

\begin{abstract}
The Office of Research and Development of the Federal Railroad Administration (FRA) and the Volpe Center have been conducting research into developing an alternative method of demonstrating the occupied volume integrity (OVI) of passenger rail equipment through a combination of testing and analysis. This research has been performed as a part of FRA Office of Research and Development's Railroad Safety Research and Development program, which provides technical data to support safety rulemaking and enforcement programs of the FRA Office of Railroad Safety. Previous works have been published on a series of full-scale, quasi-static tests intended to examine the load path through the occupant volume of conventional passenger cars retrofitted with crash energy management (CEM) systems. This paper reports on the most recent testing and analysis results.
\end{abstract}

Before performing any tests of proposed alternative loading techniques, an elastic test of the passenger car under study was conducted. The elastic test served both to aid in validating the finite element (FE) model and to verify the suitability of the test car to further loading. In January, 2011, an 800,000 pound conventional buff strength test was performed on Budd Pioneer 244. This test featured arrays of vertical, lateral, and longitudinal displacement transducers to better distinguish between the deformation modes and rigid body motions of the passenger car. Pre-test car repairs included straightening a dent in one side sill and installing patches over cracks found in the side sills. Additionally, lateral restraints were added to the test frame due to concerns in previous tests associated with lateral shift in the frame. As a part of this testing program, a future test of a passenger car is planned to examine an alternative load path through the occupied volume. In the case of Pioneer 244, this load path places load on the floor and roof energy absorber support structures. Loading the occupant volume in this manner more closely simulates the loading the car would experience during a collision.

FE analysis was used in conjunction with full-scale testing in this research effort. An FE model of the Pioneer car was constructed and the 800-kip test was analyzed. The 800-kip test results were then compared to the analysis results and the model was adjusted post-test so that satisfactory agreement was reached between the test and the model. In particular, the boundary conditions at the loading and reaction locations required careful attention to appropriately simulate the support conditions in the test. Because the 800-kip load was applied at the line of draft, this test results in significant bending as well as axial load on the car. To ensure that both the axial and bending behaviors are captured in the model, the key results that were compared between test and model are the longitudinal force-displacement behavior and the vertical deflections at various points along the car. The post-test model exhibited good agreement with the compared test results. The validated model will be used to examine the behavior of the occupant volume when loaded along the alternative load path.

\section{INTRODUCTION}

FRA is the government agency responsible for promulgating regulations to ensure the safety of railroad equipment, passengers, and crew traveling on the general railroad system in the U.S. Several regulations specify design requirements for particular structures within the passenger railcar. One such requirement is found at 49 CFR 238.203, "Static End Strength," commonly referred to as the "buff strength requirement." This part requires that

“...all passenger equipment shall resist a minimum static end load of 800,000 pounds applied on the line of draft without permanent deformation of the body structure. " [1]

This material is declared a work of the U.S. Government and is not subject to copyright protection in the United States. Approved for public release; distribution is unlimited. 
The magnitude of load applied in this fashion has evolved over the course of the $20^{\text {th }}$ century. Because the static strength requirements in other parts of the world do not require the same loading conditions, FRA has recently encountered requests for waivers from the requirements of 238.203 for equipment designed to alternative specifications [2, 3, 4, 5]. Additionally, modern railcar designs more frequently include crash energy management (CEM) features to mitigate the consequences of accidents and provide an additionally level of safety to train occupants. These features move the collision loads experienced by the occupied volume away from the conventional line of draft.

To help ensure the adequacy of the occupied volume integrity (OVI) of equipment not designed according to the conventional domestic standards, FRA's Office of Research and Development and the Volpe Center have worked with FRA's Office of Railroad Safety to develop alternative strategies for evaluating OVI in passenger railcars [6]. This work was also utilized by the Railroad Safety Advisory Committee (RSAC) Engineering Task Force, which developed a set of guidelines for evaluating alternatively-designed passenger rail equipment. These guidelines, entitled "Technical Criteria and Procedures for Evaluating the Crashworthiness and Occupant Protection Performance of Alternatively-Designed Passenger Rail Equipment for Use in Tier I Service," are intended to streamline the process of presenting technical information needed to determine equivalent safety between alternativelydesigned and fully-compliant passenger equipment in pursuit of a waiver of particular regulations. [9]

In both the FRA's research program and the ETF's work the concept of moving the compressive load away from the line of draft was considered. The line of draft, indicated schematically in Figure 1, is the imaginary line running from the coupler at one end of the car to the opposite. Depending on the design of a particular car, there may or may not be an actual structure along this line. While service loads are generally transmitted along this line for equipment with a conventional coupler and underframe arrangement, collision loads may follow a different load path through the car. This is especially true for CEM equipment, which may transmit collision loads into the occupant volume through its energy-absorbing elements.

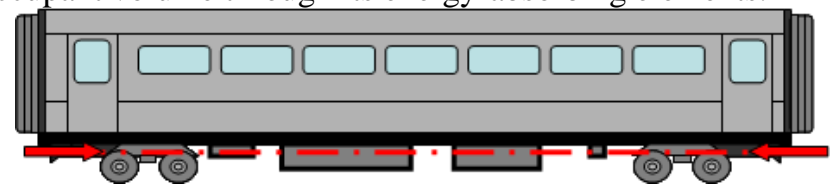

Figure 1. Schematic Line of Draft on Conventional Railcar

As a part of the Equipment Safety Research Program, FRA is performing a series of tests on the occupied volume of a passenger railcar. Previous publications on this program outlined the overall research strategy [7] and discussed preliminary elastic testing results and analysis [8]. This paper provides a detailed discussion of a conventional elastic test to 800,000 pounds and the companion finite element (FE) analysis work.

\section{Criteria and Procedures}

As a part of any testing program, criteria and procedures for performing the evaluation and interpretation of the results are needed. The criteria are defined as the conditions to be met, as well as the critical response to those conditions [9]. In the case of the conventional 800,000 pound buff strength test, the criteria are an 800,000 pound load and no permanent deformation to the carbody under such a load. The procedures are defined as the analysis and test techniques applied to evaluate compliance with the criteria. In the case of the 800,000 pound buff strength requirement, the procedures are, in general, a quasi-static compression test of a complete carbody structure. A more detailed description of the procedures for performing this sort of test is provided in the APTA Standard SS-C\&S-034-99-2 [10]. In this research program, the procedures also include the use of an FE model to simulate the response of the car in the test. However, it should be noted that analysis alone is not currently considered persuasive that a given design meets the requirements of the 800-kip regulation.

\section{TEST SETUP}

Previously, an 800,000 pound compression test of Budd Pioneer \#244 was performed on January 20, 2010 [8]. While preliminary results of this test were reported, detailed review of the test results indicated some anomalies. In particular, due to a lateral shift in the test frame, the rear end of the car was not restrained as expected during the test. Because only vertical displacement was measured on the underframe of the car during this test, there was no way to measure how this lateral shift affected the results. Additionally, cracks were discovered in the side sill of the car following the test, calling into question the car's ability to successfully sustain a load of 800,000 pounds without permanent deformation.

Due to these uncertainties, a second 800,000 pound compressive strength test of Budd Pioneer \#244 was conducted on January 19, 2011, at Transportation Technology Center (TTC) in Pueblo, CO. A patch was applied to the cracks in the side sill, with an identical patch added to the opposite side's sill to attempt to maintain a similar stiffness on both sides. A dent found in one side sill was also straightened before the test. Additional string potentiometers were added to the underside of the car to better capture motion in three dimensions. Finally, the rear end of the test frame was secured to help prevent lateral displacement of the frame during the test.

As part of a previous FRA research program, several retired commuter rail cars were retrofitted with CEM systems and

This material is declared a work of the U.S. Government and is not subject to copyright protection in the United States. Approved for public release; distribution is unlimited. 
crash tested. Pioneer \#244 had been used in five dynamic impact tests [8]. Successful completion of the 800,000 pound compressive test would verify the suitability of this car for further testing. Additionally, if the FE model were successfully validated with test data the model could then be used for further analysis of the car's behavior when loaded along the collision load path. Budd Pioneer \#244 is shown in the test frame in Figure 2. The A-end of the car is referred to as the "live end," as this is the end of the car where the load is applied. The CEM components on the ends of the car are also indicated in this figure.

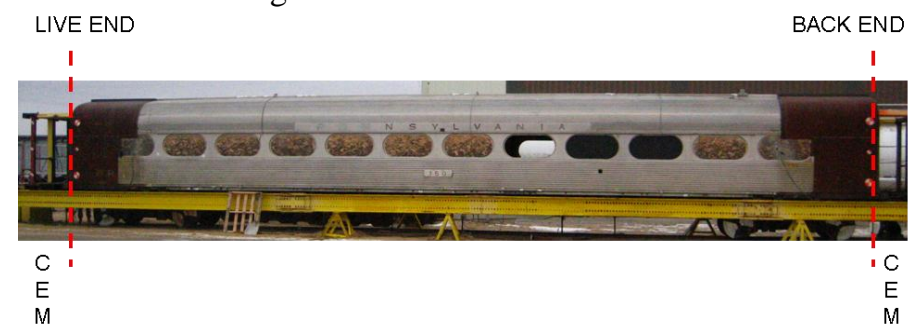

Figure 2. Budd Pioneer \#244 in Test Frame

(January 19, 2011)

\section{Instrumentation}

The critical measurements that were taken during the test were vertical, lateral, and longitudinal displacement measurements at 9 locations, strain measurements at 64 locations, and the load applied at the live end of the car. Table 1 is a summary of the data channels used in this first test.

\section{Table 1. Instrumentation from Elastic Test}

\begin{tabular}{|l|c|}
\hline $\begin{array}{c}\text { Type of } \\
\text { Instrumentation }\end{array}$ & $\begin{array}{c}\text { Number of } \\
\text { Channels }\end{array}$ \\
\hline Uniaxial Strain Gage & 64 \\
\hline String Potentiometer & 27 \\
\hline Load Cell & 1 \\
\hline Total & $\mathbf{9 2}$ \\
\hline
\end{tabular}

Because the ETF report includes a section discussing target tolerances for comparing FE results to test data, its guidance was followed for this test and the corresponding analysis. The critical measurements that were compared between the test and the FE analysis are the overall shortening of the car at a given load and the vertical deflection of the car at multiple locations. The C\&P guidelines document includes the following tolerance for comparing test measurements and analysis results that was applied in this test:

Vertical and Longitudinal Displacements: Analysis results within +/- $10 \%$ of the test measurements are acceptable for proper validation

\section{Displacement Instrumentation}

Vertical, lateral, and longitudinal displacement measurements were collected at 9 locations on the underside of the car during the 800,000 pound compressive strength test. These locations and their names are indicated on the underside of the FE model in Figure 3.

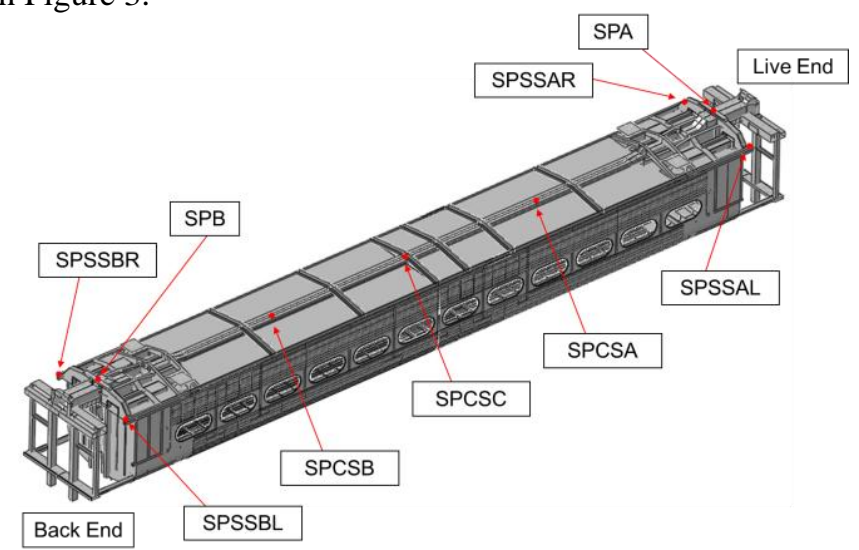

Figure 3. Locations and Names for String Pots in $\mathbf{8 0 0 , 0 0 0}$ pound Buff Test (Underside View of Model)

Vertical, lateral, and longitudinal (VLL) arrays of string potentiometers were placed at each of the locations indicated in Figure 3. At a given point, a displacement in any one direction could register as a change in string length in both of the other two directions. Displacement data collected in all three directions at a single point can be resolved into motion of that point in the vertical, lateral, and longitudinal directions. This instrumentation strategy was employed to help reduce the error introduced into the measurements by any unexpected lateral motion of the car. Figure 4 shows an exemplar VLL array at a single point.

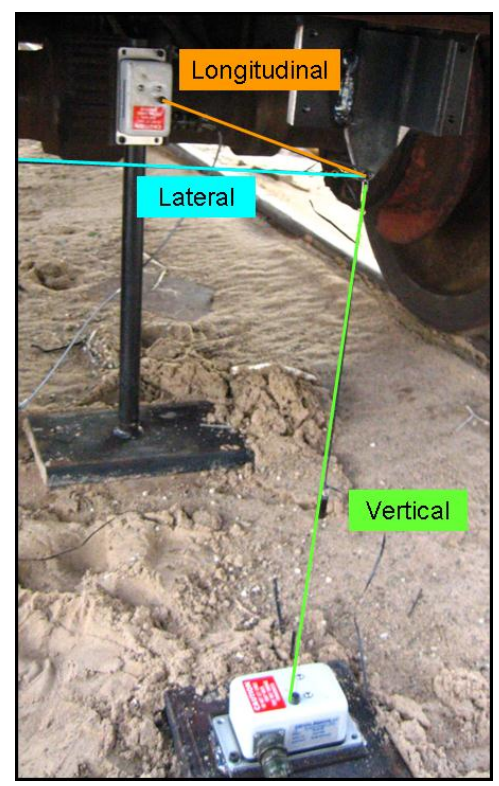

Figure 4. String Pot VLL Array

This material is declared a work of the U.S. Government and is not subject to copyright protection in the United States. Approved for public release; distribution is unlimited. 


\section{Load Cell}

In the 800 kip buff strength test, the load is applied at the live end buff stops and reacted through the back end buff stops. A single $1,000,000$ pound capacity load cell was placed in-line with the hydraulic actuator that was applying the load at the live end of the car. The hydraulic actuator and load cell arrangement is shown in Figure 5.

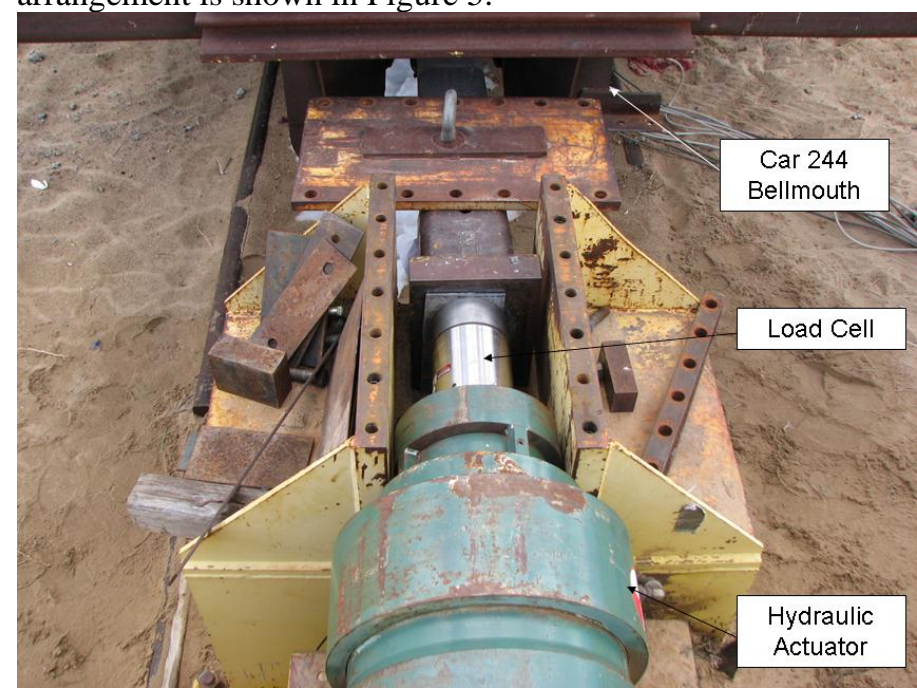

Figure 5. Hydraulic Actuator and Load Cell in 800-kip Buff Strength Test

\section{Strain Gages}

Single-direction strain gages were used to instrument the longitudinal structural members of the car at six cross-sections. These cross-sections are shown in Figure 6.

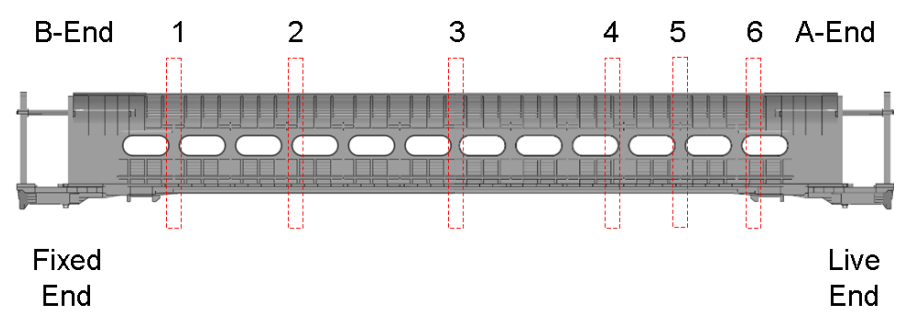

Figure 6. Cross-sections for Strain Gages, 800-kip buff strength test

At locations one through five, gages were applied to the center sill, side sills, belt rail, roof rail, and purlin. At location six, strain gages were only used on the side sill and belt rail. Figure 7 shows a cross-section of the car taken from the FE model. The members that were instrumented with strain gages and the location of the gage(s) on each member's cross-section are indicated in this figure.

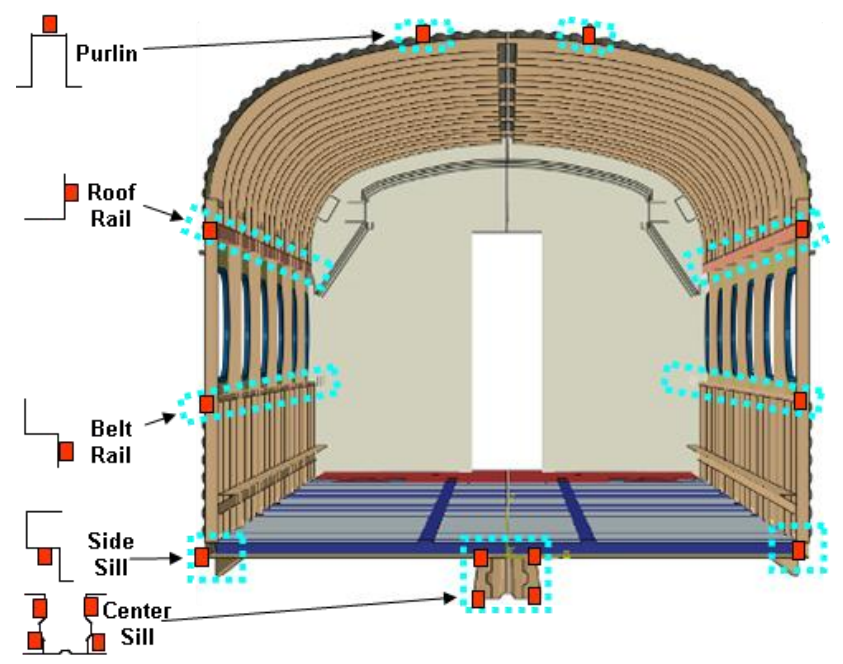

Figure 7. Cross-section of Pioneer 244 Showing Strain Gages in 800-kip Test

\section{FE MODEL SETUP}

The 800,000 pound buff strength test was simulated using the commercial finite element software Abaqus/Explicit [11]. While the test was intended to be a quasi-static loading without any permanent deformation, the analysis was simulated as a slow, dynamic loading using an explicit finite element solver. This 800-kip test's results were being used both to validate the FE model and to verify the car structure was suitable for further testing. The planned further testing includes loading the car to its ultimate, or crippling, load along its collision load path. Because an explicit finite-element solver will be needed to capture the crippling behavior of the car an explicit solver was used to simulate both the 800-kip test and the planned future test.

A half-symmetric (full length, half width) FE model was used to analyze the 800-kip load and is shown in Figure 8 . The model was composed of 223,888 elements and 220,986 nodes. The majority of the elements were shell elements. Spring elements were used to model the suspension. Solid elements were used around the window frames. Rigid elements were used to model the ground. The model had a characteristic element length of 1.37 inches.

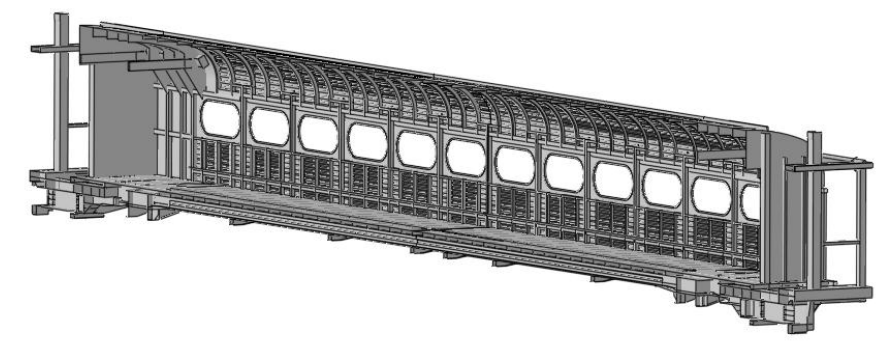

Figure 8. Half-symmetric FE Model Used in 800-kip Buff Strength Analysis

This material is declared a work of the U.S. Government and is not subject to copyright protection in the United States. Approved for public release; distribution is unlimited. 


\section{Boundary Conditions}

A symmetry boundary condition was applied to the verticallongitudinal plane along the lateral centerline of the car. This symmetry boundary condition eliminated lateral gross motion of the car and sped up the analysis, compared to modeling the complete car. As large lateral motion was not expected during this test, it was not expected that this boundary condition would have a negative influence on the modeling results.

Vertical support was provided at the two body bolsters, representing the physical location of the secondary suspension springs. A rigid part was created to simulate the ground and placed below the car body at the truck location. A constraint equation was written to maintain the same longitudinal displacement in the ground part as at the center of the body bolster. A spring was used to connect the center of the body bolster to the ground. The constraint equation held the spring vertical throughout the analysis.

Because the airbag suspension system was not inflated during the test, the carbody was free to lift off of the trucks. The physical presence of the trucks prevented the car from moving downward at the locations of the trucks. Therefore, a nonlinear spring characteristic was applied to the springs in the FE model. Each spring provided 1 million pounds/inch of resistance to downward motion but offered 1/1000 pound/inch resistance to upward motion of the car structure. The groundspring-car assembly is shown in Figure 9, which is an inverted view of the underside of the car.

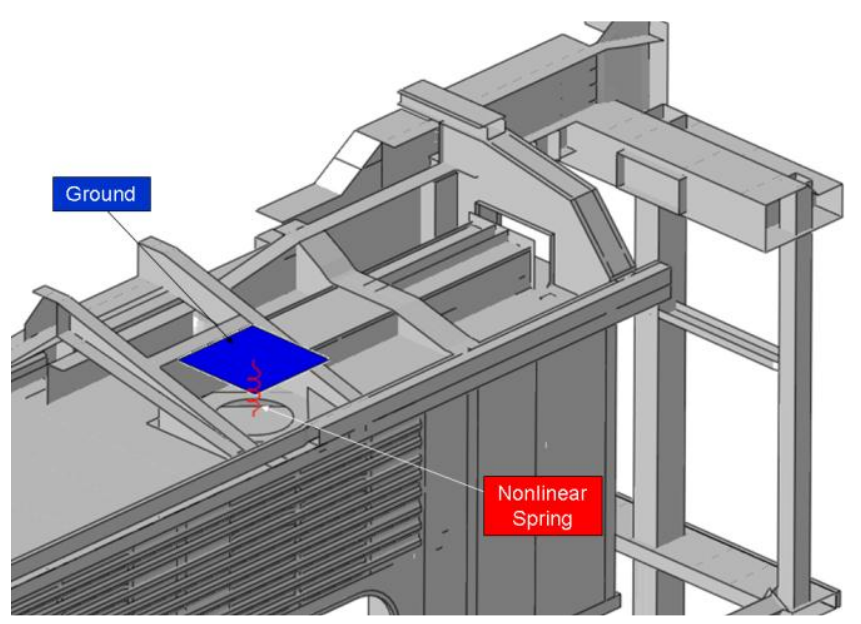

Figure 9. Nonlinear Suspension Spring in FE Model of 800kip Buff Strength Test (Underside View)

Longitudinal motion was restricted in the test by the presence of the test frame at the back end of the car. Longitudinal motion was controlled on the front end of the car by means of a hydraulic ram. Both the restraint at the back end of the car and the hydraulic actuator on the front end of the car were in contact with the buff stops within the sliding sill of the car.
Because both the hydraulic ram at the live end of the car and the frame at the back end of the car were allowed to pivot during the test, the model attempted to incorporate this behavior in the boundary conditions at both the live and the back ends of the car. At the live end, a displacement boundary condition was applied to a row of nodes at the centroid of the buff stops. The displacement was increased at a constant rate of 2 inches per second over the length of the analysis. The corresponding row of nodes on the back end buff stops was prevented from moving in the longitudinal direction. Because only the longitudinal displacement was constrained, the buff stops were free to move vertically, laterally, and rotate in response to the longitudinal load. The row of nodes used to load and restrain the car is indicated in Figure 10.

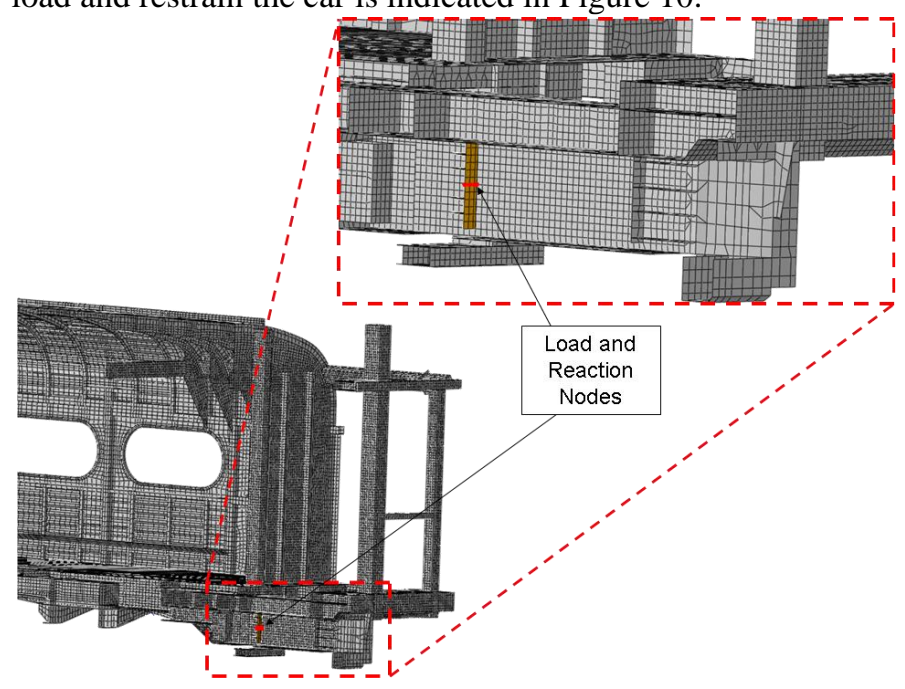

Figure 10. Load and Reaction Points on Buff Stops in 800kip Buff Strength Test

\section{Gravity Load}

The effects of gravity were included in this model. Before the 800,000 pound longitudinal load was applied to the car, gravity load step was simulated where the standing car was subjected to a $1 \mathrm{~g}$ acceleration. The weight of the half-car model was 18,825 pounds, which gives a full-car weight of 37,650 pounds. This weight is for the carbody structure alone and does not include the weight of the trucks. During a previous testing program, car 244 had 10,000 pounds of concrete added to the floor and wall structures to simulate the weight of the interior fittings and mechanical equipment that were removed from the car prior to its use in dynamic tests [12]. This ballast was not included in the model used to simulate the 800,000 pound buff strength test.

This material is declared a work of the U.S. Government and is not subject to copyright protection in the United States. Approved for public release; distribution is unlimited. 


\section{TEST AND FE ANALYSIS RESULTS}

\section{Verification of Quasi-static Behavior in Analysis}

In the ETF report, two criteria are established for determining whether a slow, dynamic analysis is sufficiently free from dynamic effects to be considered quasi-static. While an analysis that meets only one of the two criteria may be considered quasi-static for the ETF's purposes, for this research both methods of evaluation were used to examine the $\mathrm{FE}$ analysis of the 800,000 pound buff strength test. The following two conditions are taken directly from the ETF report [9].

\section{ETF Condition One}

For a given simulated load rate, the load at the live end of the model should be the same as the load at the fixed end. Load at the reaction end may vary by up to $+/-5 \%$ of the load at the live end of the model for the analysis to be considered quasi-static.

\section{ETF Condition Two}

The ratio of kinetic energy to strain energy within the structure should be small $(<5 \%)$. The ratio of kinetic energy-to-strain energy may exceed 5\% during the first $10 \%$ of the total simulation time without invalidating the analysis as quasi-static.

\section{Evaluation of Condition One}

For the FE model used to analyze the 800,000 pound buff strength test, loading was simulated by prescribing a displacement on the live end buff stops that ramped-up over time. The force that was necessary to move the buff stop nodes the prescribed distance was calculated by the solver based upon the stiffness of the car. The buff stops on the rear of the car were not allowed to translate longitudinally, providing resistance to the motion on the live end. Similarly, the forces necessary to keep the rear buff stop from moving were calculated by the solver. In this way the applied (live) load and the reaction (fixed) load can be calculated for the model. These two loads are plotted against the reduction in car length in Figure 11. A $+/-5 \%$ envelope on the live end force is also plotted in this figure.

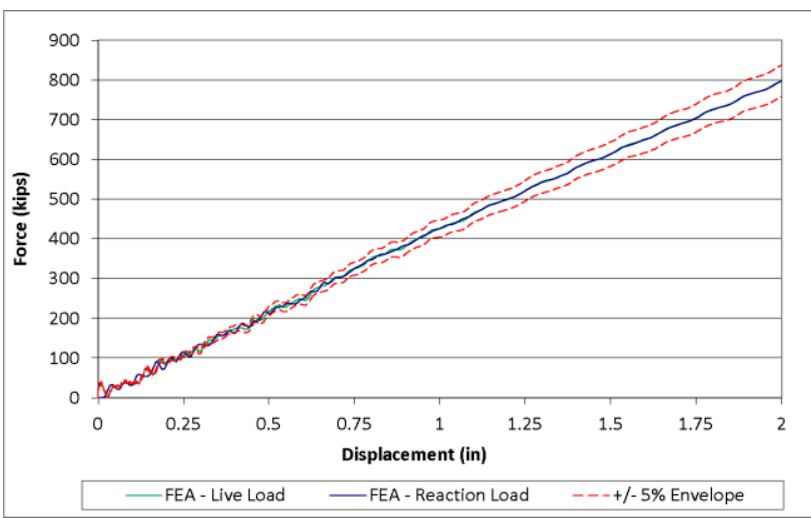

Figure 11. Live and Reaction Loads, 800 kip Buff Analysis

Figure 11 shows that the load at the live end of the car and the reaction load at the back end of the car are very close in magnitude. However, because the $+/-5 \%$ criterion is based on the live load magnitude, the envelope widens as the applied load becomes larger. At small displacements, such as below 0.5 inches, the reaction load exceeds the envelope.

Rather than invalidate the model, this tendency suggests an adjustment to the quasi-static definition as it is currently written. As the load increases, the envelope expands. Additionally, as the load magnitude increases the model tends to stabilize in its quasi-static behavior. At the critical load of 800 kips, the model behavior is sufficiently free from dynamic effects. One solution to the problem of a small envelope at low loads is to change the application of the definition from $+/-5 \%$ of the current live load to $+/-5 \%$ of the target load. In the case of the 800,000 pound compression test, this gives an envelope of constant width, +/- 40,000 pounds. The live and reaction loads are plotted against this envelope in Figure 12. The live and reaction loads do not exceed this envelope at any point during the analysis.

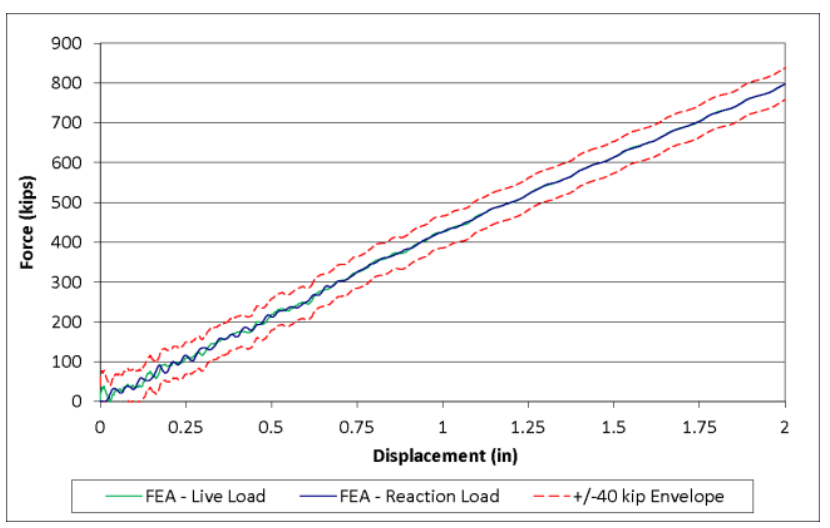

Figure 12. Live and Reaction Loads with +/-40 kip Envelope

\section{Evaluation of Condition Two}

This material is declared a work of the U.S. Government and is not subject to copyright protection in the United States. Approved for public release; distribution is unlimited. 
Because Abaqus/Explicit was being used to evaluate the 800,000 pound buff strength test, a dynamic load is being applied. The Explicit solver can calculate the total amount of kinetic energy in the system, as well as the internal (strain) energy. Because the model initially experiences very little deformation, the ratio of kinetic energy to internal energy may exceed $5 \%$ for the first $10 \%$ of the simulation time.

The ratio of kinetic energy to internal energy for the 800,000 pound buff simulation is plotted in Figure 13 on a logarithmic scale against the normalized simulation time. The simulation consisted of two steps: a gravity step and a compression load step. The transition between the two steps is indicated by a dashed vertical line in this figure. Both steps exhibit similar behavior: an initially high ratio that decreases as the car experiences more deformation.

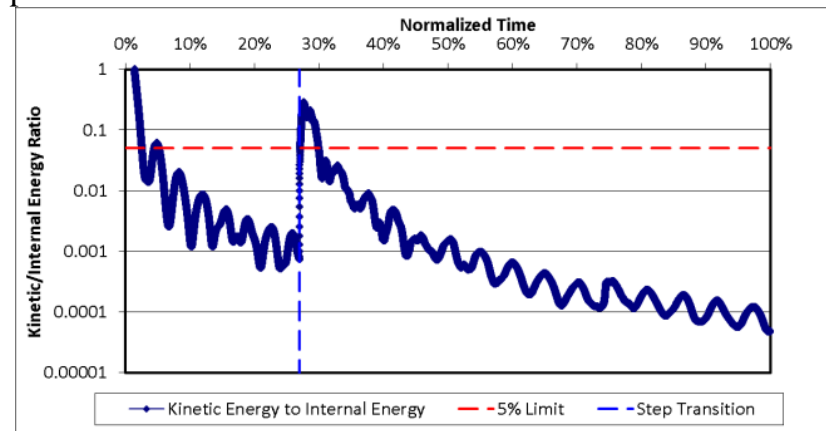

Figure 13. Ratio of Kinetic Energy to Internal Energy for 800,000 pound Simulation

Figure 13 shows that the ratio of kinetic energy to internal energy is well below 5\% for nearly the entire length of the simulation. According to ETF Condition Two, the simulation of the 800,000 pound buff strength test can be considered quasi-static.

\section{Comparison of Longitudinal Displacement Data}

Because lateral symmetry is employed in the FE model, only 7 of the 9 VLL array locations in the test are represented in the model. Overall force-displacement data from both the test and the model are plotted in Figure 14. As recommended in the ETF report, $a+/-10 \%$ envelope of the test forces is also plotted for comparison purposes. The displacement test data used in the horizontal axis is the difference between the longitudinal displacement at the live end and at the back end of the car. There is very good agreement between the test results and the model data at all load magnitudes.

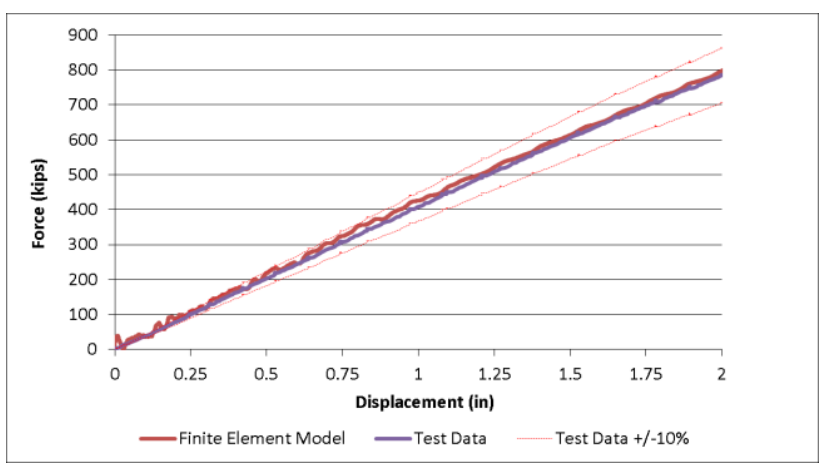

Figure 14. Force-displacement Results from 800,000 pound Test and FE Model

Longitudinal displacement data was also compared between the test and the model at each of the other instrumented locations (see Figure 3). In each case, the longitudinal displacement at the back (non-live) end of the car was subtracted to remove the rigid body motion component associated with expansion of the test frame. The following series of figures (Figure 16 through Figure 19) compares the longitudinal displacement data versus the applied load of the test with that of the model at each of the relevant locations.

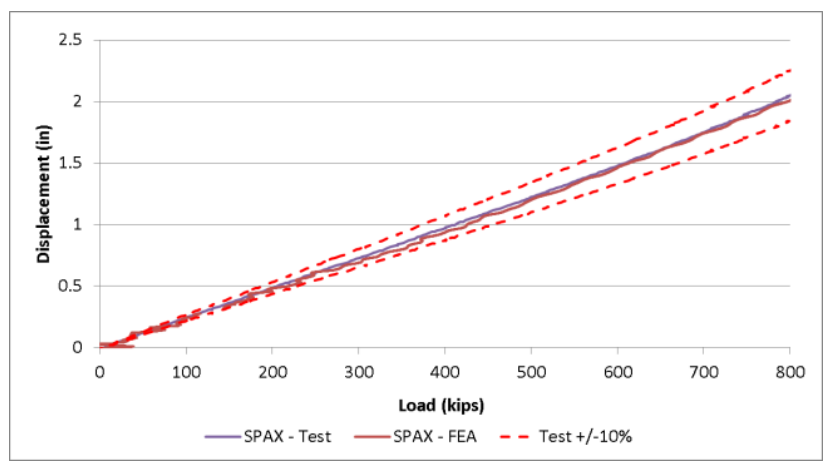

Figure 15. Longitudinal Displacement at Live End of Car

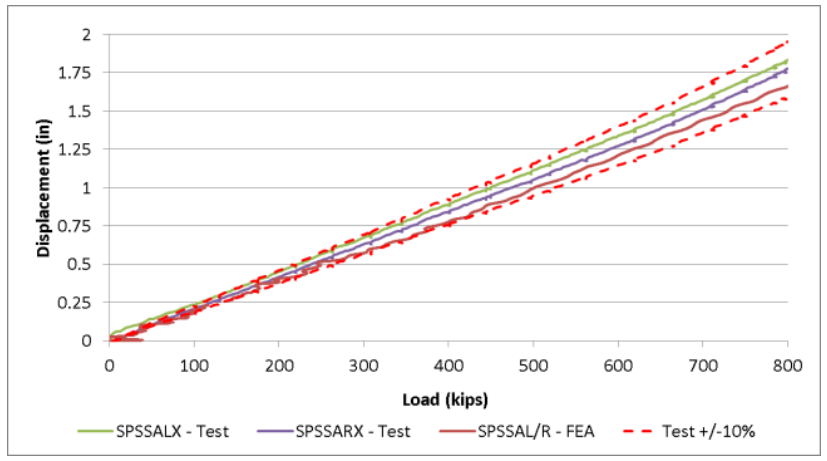

Figure 16. Longitudinal Displacement at Live End Side Sills

This material is declared a work of the U.S. Government and is not subject to copyright protection in the United States. Approved for public release; distribution is unlimited. 


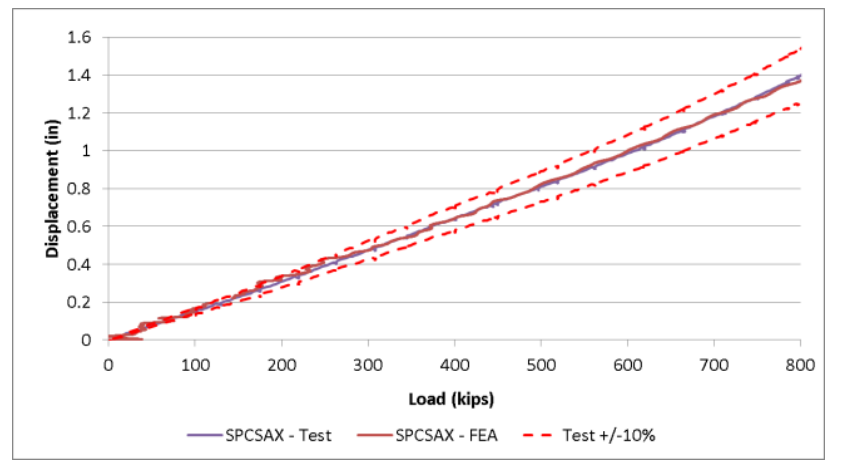

Figure 17. Longitudinal Displacement at A-end Center Sill

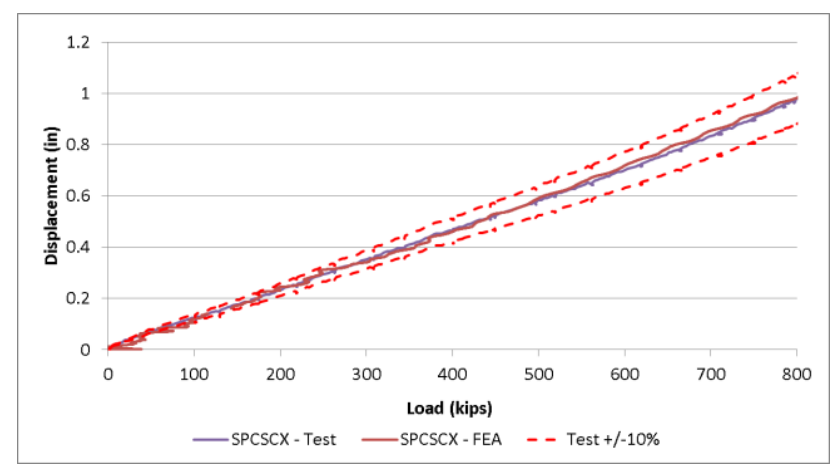

Figure 18. Longitudinal Displacement at Mid-car Center Sill

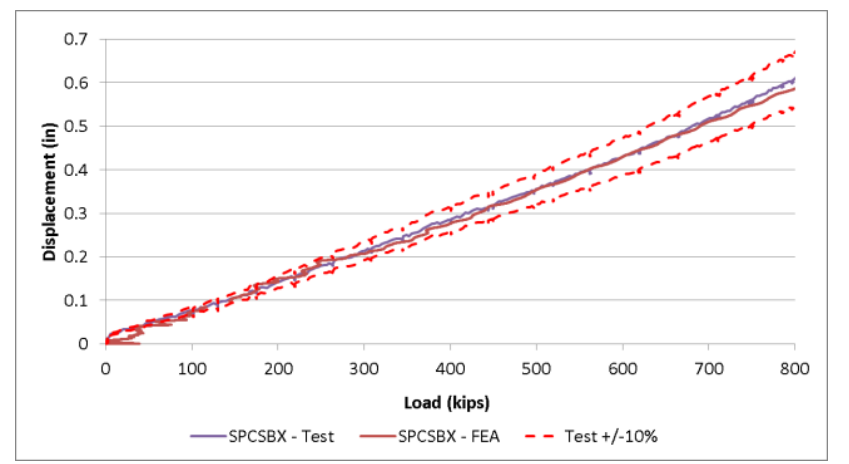

Figure 19. Longitudinal Displacement at B-end Center Sill

\section{Comparison of Vertical Displacement Data}

Vertical displacement data was collected at the same 9 locations as longitudinal displacement data during the test. Because of the symmetry employed in the FE model, vertical displacement data was calculated at 7 locations in the model.

Figure 20 shows a plot of vertical displacement at 5 locations along the length of the car measured during the test. In this plot, the five points have been connected by regression curves to interpolate the behavior of the car between the instrumented locations. The horizontal axis has its zero at the first live-end cross section where vertical displacement data was measured. Each series represents the vertical displacement of the car at a different load increment. The locations of the extents of the two body bolsters (where the trucks are supporting the car) are indicated using dashed lines.

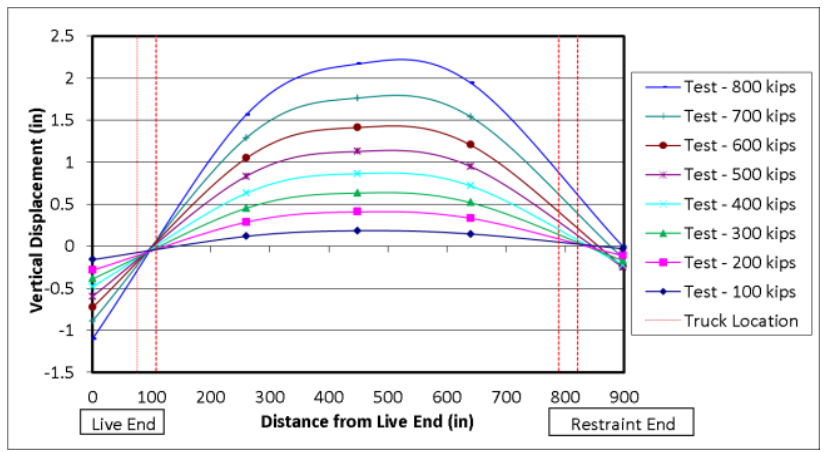

Figure 20. Vertical Displacement Along Length of Car, Test Data

As seen in this figure, the ends of the car tend to move down and the center of the car tends to lift upward under the line of draft load. On the live end of the car, the regression line at each load magnitude changes from downward motion to upward motion at a location that coincides with the center of the body bolster, indicating that the live-end truck is acting as a pivot point.

At the rear end of the car the displacement behavior is slightly different than at the live end. The back end displacements at the last cross-section are all downward but of smaller magnitudes than at the live end. Additionally, the regression line for each load magnitude does not transition from positive to negative displacement at the back end bolster.

The vertical displacement data from the cross-section closest to the back end of the car is plotted in Figure 21 versus the applied load for string pots on both the left and right side sills. As seen in this figure, the vertical displacement data does not begin at a zero value for both left and right channels. However, the behavior is qualitatively similar. As the load is increased, the end of the car moves downward. This is similar to the live end behavior. At a longitudinal load of more than 500 kips, the back end of the car changes behavior and begins to move back upward as the load is increased. This behavior is not seen on the live end test data.

This material is declared a work of the U.S. Government and is not subject to copyright protection in the United States. Approved for public release; distribution is unlimited. 


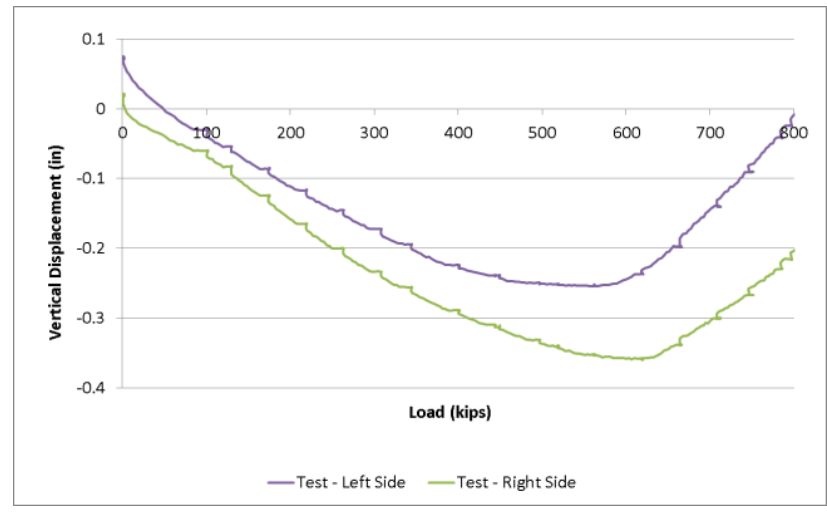

Figure 21. Vertical Displacement at Back End of Car, 800kip Buff Strength Test

There are several possible explanations for this behavior. The test frame rests upon a series of supports along its length. At the live end of the car, the frame is bolted to a concrete foundation. Along the rest of its length the beams making up the frame are sitting upon supports. At the back end of the frame, the only force able to resist upward motion of the frame is its own weight. A second possible explanation for this change in behavior is contact between the reaction column within the draft sill and the draft sill itself. This non-linear behavior was incorporated in the FE model through the use of a non-linear spring characteristic applied to the back end buff stops.

The vertical displacement results obtained from the FE model are plotted in Figure 22. Each line represents the deflection of the car at a particular load magnitude. Qualitatively, the results resemble the test data plotted in Figure 20. The live end of the model car is seen to move downward as the load in increased. The back end of the car initially moves downward as well. However, at approximately 250 kips of longitudinal load the downward motion is arrested and the rear end begins to move upward because of the non-linear springs used at the rear end buff stops in the model.

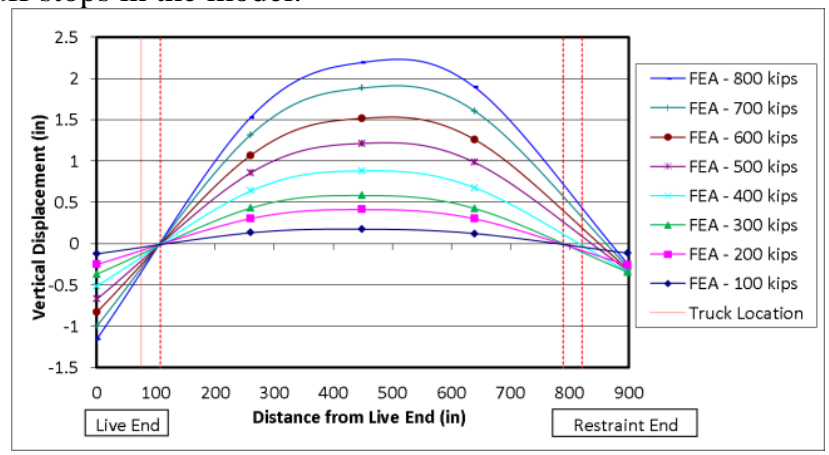

Figure 22. Vertical Displacement Along Length of Car, Finite Element Results

Vertical displacement data is plotted at each string pot location in the car (Figure 3) and at each simulated location in the FE model in Figure 23 through Figure 29. This sequence of plots is presented moving from the live end of the car to the back end of the car. A +/- $10 \%$ envelope of test data is shown in each plot as well.

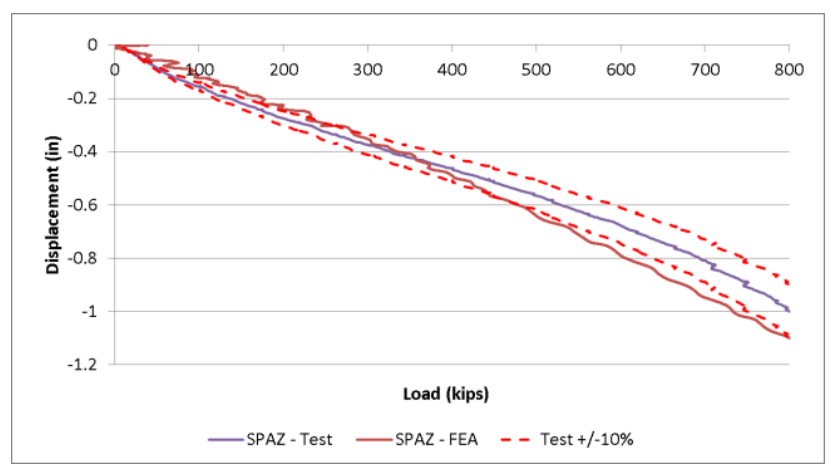

Figure 23. Vertical Displacement in Test and Analysis, Center of A-end of Car

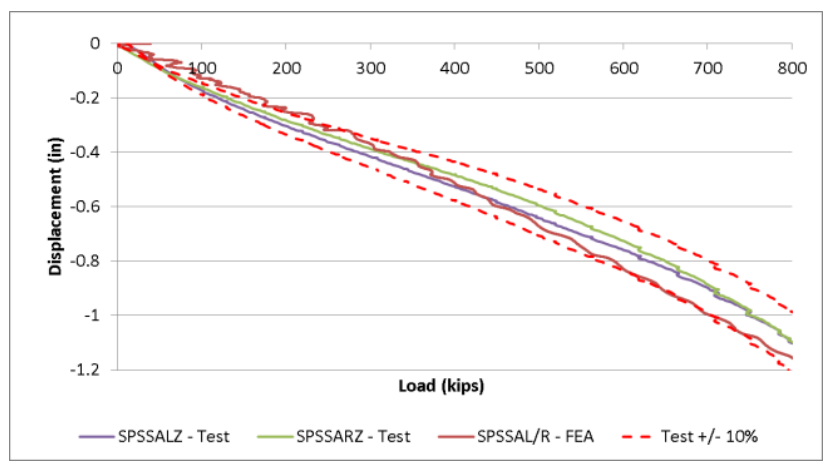

Figure 24. Vertical Displacement in Test and Analysis, Live End Side Sills

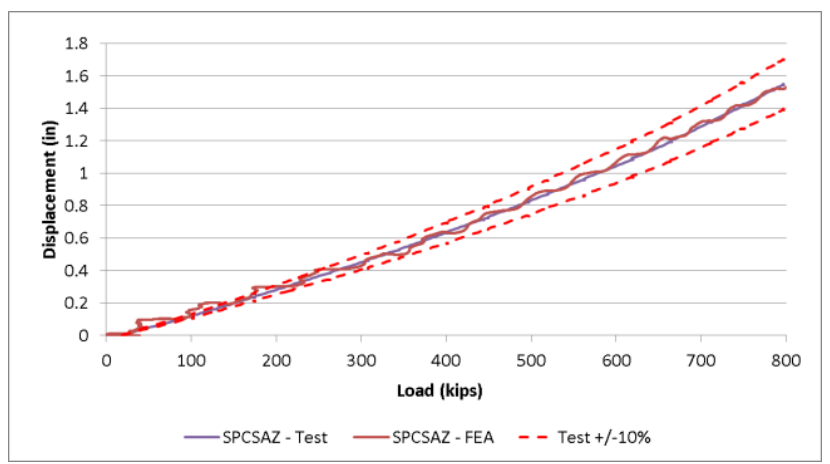

Figure 25. Vertical Displacement in Test and Analysis, A-end Center Sill

This material is declared a work of the U.S. Government and is not subject to copyright protection in the United States. Approved for public release; distribution is unlimited. 


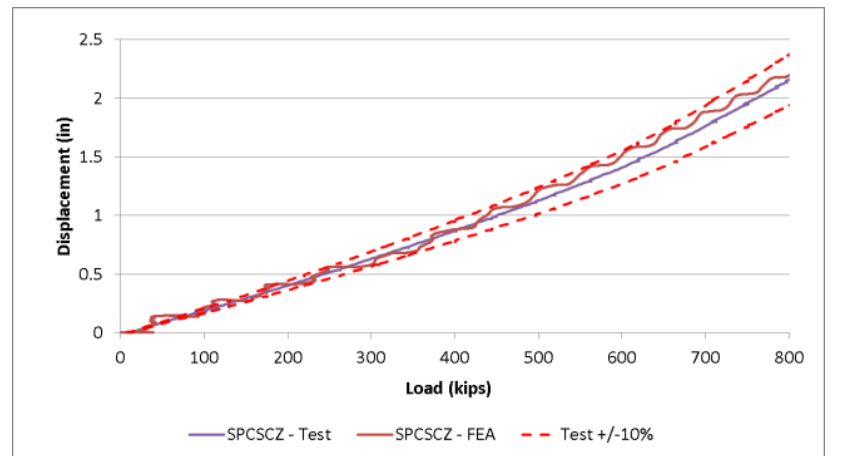

Figure 26. Vertical Displacement in Test and Analysis, Mid-car Center Sill

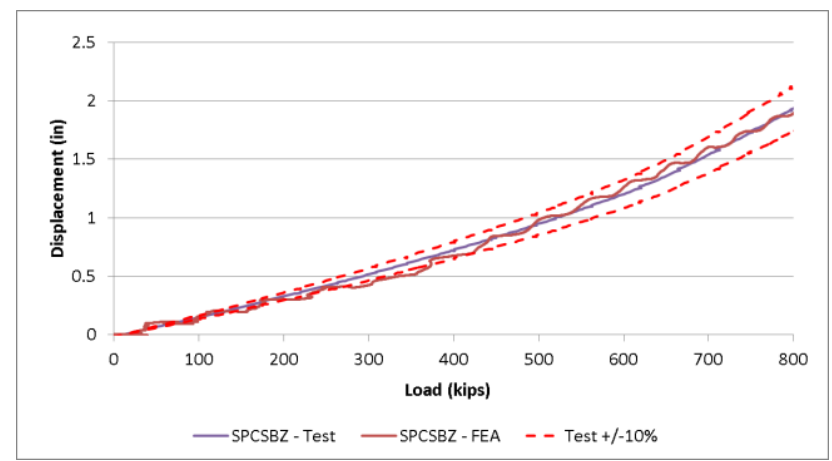

Figure 27. Vertical Displacements in Test and Analysis, B-end Center Sill

At the rear end of the car the effects of the non-linear spring on the vertical deflection behavior can be observed in Figure 28 and Figure 29. The FE model results indicate a qualitatively similar behavior to the test data, though not at the same load magnitudes. However, further tuning of the spring stiffness used in the model could result in a closer approximation of the rear support condition of the car during the test.

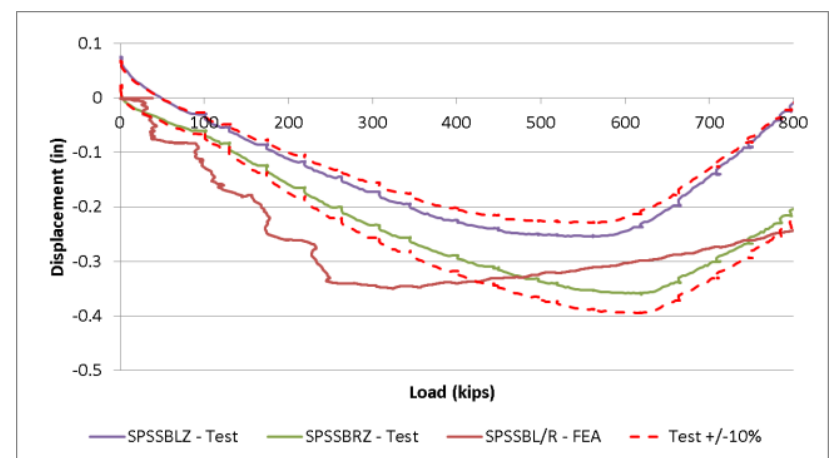

Figure 28. Vertical Displacement in Test and Analysis, Back End Side Sills

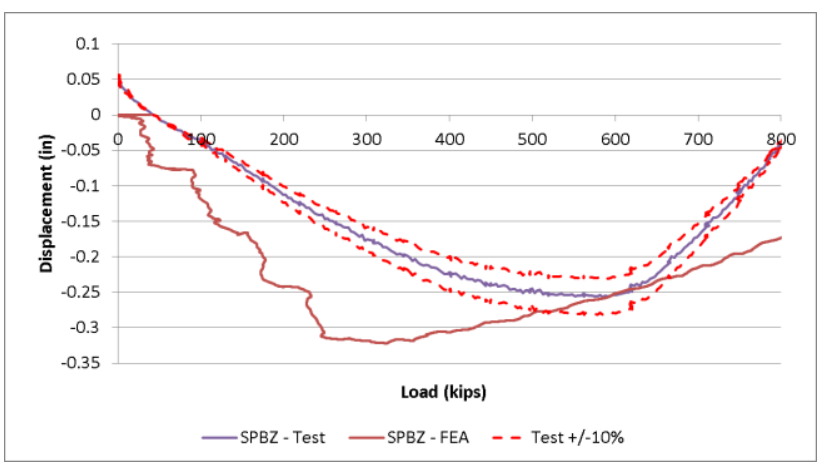

Figure 29. Vertical Displacement in Test and Analysis, Center of Back End of Car

Overall there is good agreement between the measured vertical deflections of the car during the test and the vertical displacements calculated by the FE model. In particular, the upward vertical deflections of the center sill between the body bolsters (shown in Figure 25 through Figure 27) display very good agreement between the test and the analysis.

\section{CONCLUSIONS}

An 800,000 pound compressive strength test of Budd Pioneer \#244 was conducted on January 19, 2011. Prior to this test, the car was repaired to straighten a dented side sill and patch two cracks that were found in the side sill following a previous test. This test loaded a passenger railcar along its line of draft to examine the elastic behavior of the car.

FE modeling was performed in conjunction with this test. The major comparisions made between the FE model and the test data included the longitudinal load-displacement behavior of the entire car, the longitudinal deflections of several crosssections, and the vertical deflection of the underframe at multiple locations. Overall, the FE results were in good agreement with the test data, indicating the model is capturing the overall behavior of the car under these load conditions.

\section{FUTURE WORK}

As a part of this research program, a further test of Pioneer \#244 is planned. In this test, the CEM structures will be removed from the car and the occupant volume will be loaded at the locations where CEM loads would be transmitted through the occupant volume during a collision. This test will load the car until its ultimate, or crippling, load is reached.

In support of the crippling test, the FE model that was validated by the 800,000 pound buff strength test will be used to model the crippling behavior of the car. The results of the crippling test and the crippling FE model will be compared. It is envisioned that in the future, the methodology of validating an FE model with elastic test data and then using that FE model to extrapolate up to the crippling behavior of a car of interest will be applied to demonstrate OVI. This research program seeks to

This material is declared a work of the U.S. Government and is not subject to copyright protection in the United States. Approved for public release; distribution is unlimited. 
examine the efficacy of using this methodology to evaluate the OVI of a passenger car along an alternative load path.

\section{ACKNOWLEDGEMENTS}

This work was performed by the Volpe Center as part of the Equipment Safety Research Program sponsored by the Office of Research and Development of the Federal Railroad Administration. Mr. Kevin Kesler is Chief of the Equipment and Operating Practices Division. The fullscale testing was performed by Transportation Technology Center, Inc. The Budd Pioneer cars utilized in this research program were donated by SEPTA.

\section{REFERENCES}

1. Static End Strength, 49 CFR 238.203.

2. Petition of Capital Metropolitan Transportation Authority for Shared Lease and Waiver of Federal Railroad Administration Regulations. Docket No. FRA-2006-25040.

3. Petition of the Denton County Transportation Authority for Waiver Acceptance of non-Compliant Self-Propelled Rail Vehicles (Stadler GTW 2/6 Diesel Multiple Units). Docket No. FRA-2010-0180.

4. Petition of Peninsula Corridor Joint Powers Board/Caltrain for Approval of Mixed Use and Waiver of Certain Federal Railroad Administration Regulations. Docket No.FRA2009-0124.

5. DesertXpress Enterprises, LLC's Petition for Waivers from Federal Railroad Administration Regulations. Docket No.FRA-2010-0098.

6. Carolan, M., Perlman, B.A., Tyrell, D., "Evaluation of Occupant Volume Strength in Conventional Passenger Railroad Equipment" American Society of Mechanical Engineers, Paper No. RTDF2008-74026, September 2008.

7. Carolan, M., Muhlanger, M., "Strategy for Alternative Occupant Volume Testing" American Society of Mechanical Engineers, Paper No. RTDF2009-18025, October 2009.

8. Carolan, M., Muhlanger, M.P. "Update on Alternative Occupant Volume Testing." American Society of Mechanical Engineers, Paper No. JRC2010-36020., April 2010.

9. "Technical Criteria and Procedures for Evaluating the Crashworthiness and Occupant Protection Performance of Alternatively-Designed Passenger Rail Equipment for Use in Tier I Service. “ U.S. Department of Transportation, Federal Railroad Administration, 2011 (Draft).
10. American Passenger Transportation Association, "APTA SS-C\&S-034-99, Rev. 2. Standard for the Design and Construction of Passenger Railroad Rolling Stock," June 15, 2006.

11. Dassault Systèmes, 2010. Abaqus 6.10-1.

12. MacNeil, R., Kirkpatrick, S., "Vehicle Postmortem and Data Analysis of a Passenger Rail Car Collision Test," Proceedings of the 2002 IEEE/ASME Joint Railroad Conference, Institute of Electrical and Electronics Engineers, Catalog Number CH37356-TBR, 2002.

This material is declared a work of the U.S. Government and is not subject to copyright protection in the United States. Approved for public release; distribution is unlimited. 